\title{
Infant and young child feeding practices in a rural area of North India
}

\author{
Mahesh Satija', Sarit Sharma ${ }^{2}$, Anurag Chaudhary ${ }^{3}$, Pushapindra Kaushal ${ }^{4}$, Sangeeta Girdhar ${ }^{2}$ \\ ${ }^{1}$ Associate Professor, ${ }^{2}$ Professor, ${ }^{3}$ Professor and Head, ${ }^{4}$ Assistant professor, Department of Community Medicine, Dayanand Medical College \\ \& Hospital, Ludhiana, Punjab-141001, Punjab, India
}

\section{A B S T R A C T}

Background: Infant and young child feeding practices directly affect the nutritional status of children under two years of age and, ultimately, impact child survival. Therefore, the objective of this study was to assess the WHO infant and child feeding indicators in a rural area of Ludhiana, Punjab, India. Methods: A community based cross sectional study was conducted in fifteen villages of Ludhiana district under rural health training centre of Department of Community Medicine, Dayanand Medical College \& Hospital, Ludhiana, Punjab. The data was obtained from mothers/primary caregivers of 813 living children 0-23 months of age group and information about seven core and three optional WHO infant and young child feeding indicators was collected using WHO questionnaire. Prevalence estimates with $95 \%$ confidence interval were calculated. A $\chi^{2}$ test and Odds Ratio (OR) with $95 \% \mathrm{Cl}$ was calculated wherever required. Results: Only $56.7 \%$ of infants were put to breast within one hour of birth, while three fourths of infants younger than 6 months were exclusively breastfed. About seventy percent of children aged 12-15 months and $54.7 \%$ of children 20-23 months continued breastfeeding at $1 \& 2$ years respectively. Almost all the children born in the last 23 months were ever breastfed. Nearly ninety percent of infants 6-8 months of age were fed with complimentary foods at the recommended daily frequency. Conclusion: To improve breastfeeding practices, health education needs to be strengthened for target population having sub-optimal breastfeeding indicators.

Key words: Breastfeeding, Infant and young child feeding, Breastfeeding practices, India

\section{INTRODUCTION}

Infant and young child nutrition has been engaging the attention of scientists and planners since long for the very simple reason that growth rate in the life of human beings is maximum during the first year of life. Infant feeding practices comprising of both the breastfeeding as well as the complementary feeding have major role in determining the nutritional status of the child and the link between malnutrition and infant feeding has been well established. ${ }^{1}$ Malnutrition underlies a majority of under five deaths, $70 \%$ of which occur in the first year of life. ${ }^{2}$ Estimated $32 \%$, or 186 million, children aged below five years in developing countries are stunted and about $10 \%$ or 55 million are wasted. Unless massive improvements are made, it will be difficult to achieve Millennium Development Goals 1 and 4 by $2015 .^{3}$
Infant and young child feeding practices (IYCF) directly affect the nutritional status of children under two years of age and, ultimately, impact child survival. Improving these practices in children aged 0-23 months is therefore critical to improved nutrition, health and development of children. ${ }^{4}$ Marriot et al analyzed WHO infant and young child feeding indicators and associations with growth measures in 14 low income countries using Demographic and Health Survey (DHS) data and observed that early initiation of breastfeeding and meeting the complementary feeding guidelines was highly associated with lowered risk of stunting and underweight. ${ }^{5}$

Simple, valid, and reliable indicators are essential to track progress and guide investment to improve nutrition and health during first two years of life. In 1991, WHO and UNICEF published indicators for assessing breastfeeding 
practices that have since been widely measured. However, until recently these indicators have not been very informative. Therefore, WHO published a document containing definitions ${ }^{4}$ and measurement ${ }^{6}$ of updated set of indicators for assessing IYCF practices in 2008. Jones et al after studying association of these feeding indicators with child anthropometry using recent Demographic and Health Surveys data from a total of nine countries in Sub-Saharan Africa, Asia and the Caribbean also stated that the WHO indicators are clearly valuable tools for broadly assessing the quality of child diets and for monitoring population trends in IYCF practices over time. ${ }^{7}$

The Government of India, in consonance with Indian traditions has always been promoting exclusive breastfeeding for first six months and introduction of complementary foods (Annaprashan ceremony) with continued breastfeeding up to two years at the national and international foray. ${ }^{1}$ Although breastfeeding is almost universal in India, these breastfeeding rates are far from desirable. Three National Family Health Surveys (NFHS) and various studies conducted in India over the years provide a valuable source of data about these practices. ${ }^{8}$ However, fewer studies have been done using standard WHO infant and young child feeding indicators. Thus the present study was an attempt to fill this information gap about the current situation by assessing these WHO standard feeding indicators in a rural area of Punjab, India.

\section{MATERIALS AND METHODS}

The present study was conducted in 15 villages of Ludhiana district, under rural health training centre of
Department of Community Medicine, Dayanand Medical College, Ludhiana, Punjab, India. Married women in the age group 15-45 yrs receive continuous home-based reproductive care by the health workers of the training centre and are supervised by the faculty of the department. Registration of pregnancies is almost $100 \%$ in these villages, and the outcome of pregnancies is known and recorded. This is the starting point of regular and continuous child care services from birth to 5 years of age. The present cross-sectional study was carried out in these villages, where data was obtained from mothers or primary caregivers of all living children 0-23 months of age over a period of one year.

The data was collected using WHO questionnaire ${ }^{6}$ which was simplified according to the local conditions and pretested. A total of ten WHO infant and young child feeding indicators (seven core and three optional) were studied (Table 1). ${ }^{3,4}$ Except for the indicators "early initiation of breastfeeding" and "children ever breastfed", all indicators are based on current status data, i.e., the current age of the child and other information for the day preceding the survey, rather than on retrospective data. The previous-day recall period was selected because it has been widely used and found appropriate in surveys of dietary intake when the objective is to describe infant feeding practices in population. ${ }^{4}$ The research protocol was in accordance with the institution's ethical standards.

Our analysis was restricted to 813 living children less than 24 months. The Taylor series linearization method was used to estimate confidence intervals (CI) around prevalence estimates. A $\chi^{2}$ test was used to test the significance of

\begin{tabular}{|c|c|}
\hline Core Indicators & Optional Indicators \\
\hline $\begin{array}{l}\text { 1. Early initiation of breastfeeding: } \\
\text { Proportion of children born in the last } 24 \text { months who } \\
\text { were put to breast within one hour of birth } \\
\text { 2. Exclusive breastfeeding under } 6 \text { months: } \\
\text { Proportion of infants } 0-5 \text { months of age who are fed } \\
\text { exclusively with breastmilk } \\
\text { 3. Continued breastfeeding at one year: } \\
\text { Proportion of children } 12-15 \text { months of age who are } \\
\text { fed breastmilk } \\
\text { 4. Introduction of solid, semi-solid or soft foods: } \\
\text { Proportion of infants } 6-8 \text { months of age who receive } \\
\text { solid, semi-solid or soft foods } \\
\text { 5. Minimum dietary diversity: } \\
\text { Proportion of children } 6-23 \text { months of age who receive } \\
\text { foods from } 4 \text { or more food groups } \\
\text { 6. Minimum meal frequency (Breastfed children): } \\
\text { Proportion of breastfed children } 6 \text { - } 23 \text { months of age } \\
\text { who receive solid, semi-solid, soft foods the minimum } \\
\text { number of times or more } \\
\text { 7. Minimum acceptable diet (Breastfed children): } \\
\text { Proportion of children } 6-23 \text { months of age who receive } \\
\text { a minimum acceptable diet (apart from breastmilk) }\end{array}$ & $\begin{array}{l}\text { 8. Children ever breastfed: } \\
\text { Proportion of children born in the last } \\
24 \text { months who were ever breastfed } \\
\text { 9. Continued breastfeeding at } 2 \text { years: } \\
\text { Proportion of children } 20-23 \text { months } \\
\text { of age who are fed breastmilk } \\
\text { 10. Bottle feeding: } \\
\text { Proportion of children } 0-23 \text { months } \\
\text { of age who are fed with a bottle }\end{array}$ \\
\hline
\end{tabular}


associations and Odds Ratio (OR) with 95\% CI was calculated to estimate the strength of association wherever required. Analysis was performed using Epi info (TM) version 3.3.2 (2004) and Statistical Package for Social Sciences (SPSS package), version 20 (IBM SPSS statistics 20.0.0, 2011).

\section{RESULTS}

The baseline characteristics show that about one third $(35.7 \%)$ of the children were less than 6 months age group and $54.1 \%$ were males and $45.9 \%$ were females with a male-female ratio of 1.2 .

More than half of the children $(56.7 \%)$ born in the last 23 months were put to breast within one hour of birth. As per 24-hour recall, $75.9 \%$ of the infants younger than 6 months were exclusively breast fed. $70.9 \%$ of children aged $12-15$ months and $54.7 \%$ of children $20-23$ months continued breastfeeding at $1 \& 2$ years respectively. Almost all the children born in the last 23 months were ever breastfed $(98.4 \%)$ and about one quarter of these children $(25.8 \%)$ were bottle fed from birth to less than 24 months of age. Prevalence of early initiation of breastfeeding was significantly lower $(52.1 \%)$ for live births occurring in the last 11 months than for live births $(62.6 \%)$ occurring between the last 12 and 23 months $(\mathrm{OR}=0.65 ; 95 \%$ CI: $0.48,0.87$ indicating a decrease in prevalence of early initiation of breast feeding over the time. However no age specific difference was observed for children ever breast fed over the same time (OR=1.49; 95\% CI: 0.42, 5.43) (Table 2).

The study revealed insufficient milk secretion $(28.4 \%, 31.4 \%)$ and unawareness $(20.7 \%, 40 \%)$ as the reasons for delayed initiation of breastfeeding and stopping exclusive breastfeeding respectively. Similarly insufficient milk secretion and unawareness were the most common factors for discontinuing breastfeeding at one year (12-15 months) \& two years (20-23 months) and starting bottle feeding respectively. Early initiation of breastfeeding $(58.7 \%$ vs. $55 \%, \mathrm{OR}=0.85 ; 95 \% \mathrm{CI}: 0.64,1.134)$ and exclusive breastfeeding $(77.1 \%$ vs $74.8 \%$, OR $=0.88 ; 95 \%$ CI: $0.49,1.57)$ were observed to be marginally higher in females as compared to males respectively.

Majority of the infants $(89.3 \%)$ of $6-8$ months of age were fed with complimentary foods at the recommended daily frequency. Majority of breastfed children aged 6-24 months (87.0\%) had minimum dietary diversity and rates significantly increased from $77.6 \%$ in infants aged between six months \& one year to $92.8 \%$ for children aged between 18 months $\& 24$ months $\left(\chi^{2}=19.52, \mathrm{df}=2\right.$, $\mathrm{p}=0.0001)($ Table 3).

\section{DISCUSSION}

Optimal infant and young child feeding practices especially early initiation and exclusive breastfeeding for the first six months of life help ensure young children the best possible start to life. Early and exclusive breastfeeding is now recognized as one of the most effective interventions for child survival. ${ }^{9}$ The present study revealed that $56.7 \%$ of the children born in the last 23 months were put to breast within one hour of birth, while NFHS-3 conducted in 2005-06 showed that the initiation of breastfeeding was only $22.4 \%$ and $10 \%$ for rural India ${ }^{10}$ and Punjab ${ }^{11}$ respectively. District Level Health Survey (DLHS) conducted 2 years later in 2007-08 showed improvement in

\begin{tabular}{|c|c|c|c|c|}
\hline \multirow[t]{2}{*}{ Indicator } & \multicolumn{2}{|c|}{$\mathbf{N}$} & \multirow{2}{*}{$\begin{array}{c}\text { Rate } \\
(\%)\end{array}$} & \multirow[t]{2}{*}{$95 \% \mathrm{Cl}$} \\
\hline & Children & Practices & & \\
\hline Early initiation of breastfeeding $0-23$ months & 813 & 461 & 56.7 & $(53.2-60.1)$ \\
\hline Early initiation of breastfeeding $0-11$ months ${ }^{*}$ & 455 & 237 & 52.1 & $(47.4-56.8)$ \\
\hline Early initiation of breastfeeding $12-23$ months* & 358 & 224 & 62.6 & $(57.3-67.6)$ \\
\hline Children ever breastfed 0-23 months & 813 & 800 & 98.4 & $(97.2-99.1)$ \\
\hline Children ever breastfed 0-11 months ${ }^{* *}$ & 455 & 449 & 98.7 & $(97.0-99.5)$ \\
\hline Children ever breastfed $12-23$ months ${ }^{* *}$ & 358 & 351 & 98.0 & $(95.8-99.1)$ \\
\hline Exclusive breastfeeding $0-5$ months & 290 & 220 & 75.9 & $(70.5-80.7)$ \\
\hline Exclusive breastfeeding $0-1$ months $^{+}$ & 90 & 74 & 82.2 & $(72.7-89.5)$ \\
\hline Exclusive breastfeeding 2-3 months ${ }^{+}$ & 88 & 68 & 77.3 & $(67.1-85.5)$ \\
\hline Exclusive breastfeeding 4-5 months ${ }^{+}$ & 112 & 78 & 69.6 & $(60.2-78.0)$ \\
\hline Exclusive breastfeeding $0-3$ months & 178 & 142 & 79.8 & $(73.1-85.4)$ \\
\hline Continued breastfeeding at 1 year & 165 & 117 & 70.9 & $(63.3-77.7)$ \\
\hline Continued breastfeeding at 2 years & 75 & 41 & 54.7 & $(42.1-65.5)$ \\
\hline Bottle feeding 0-23 months & 813 & 210 & 25.8 & $(22.9-29.0)$ \\
\hline Bottle feeding $0-5$ months ${ }^{++}$ & 290 & 40 & 13.8 & $(10.0-18.3)$ \\
\hline Bottle feeding 6-11 months ${ }^{++}$ & 165 & 44 & 26.7 & $(20.1-34.1)$ \\
\hline Bottle feeding $12-23$ months $^{++}$ & 358 & 126 & 35.2 & $(30.3-40.4)$ \\
\hline
\end{tabular}




\begin{tabular}{|c|c|c|c|c|}
\hline \multirow[t]{2}{*}{ Indicator } & \multicolumn{2}{|c|}{$\mathbf{N}$} & \multirow{2}{*}{$\begin{array}{c}\text { Rate } \\
(\%)\end{array}$} & \multirow[t]{2}{*}{$95 \% \mathrm{Cl}$} \\
\hline & Children & Practices & & \\
\hline Introduction of solid, semisolid foods $6-8$ months & 103 & 92 & 89.3 & $80.7,93.9$ \\
\hline Minimum dietary diversity 6-23 months & 455 & 523 & 87.0 & $83.7,89.7$ \\
\hline Minimum dietary diversity 6-11 months & 165 & 128 & 77.6 & $70.4,83.7$ \\
\hline Minimum dietary diversity $12-17$ months $^{\#}$ & 191 & 172 & 90.1 & $84.9,93.9$ \\
\hline Minimum dietary diversity $18-23$ months" & 167 & 155 & 92.8 & $87.8,96.2$ \\
\hline Minimum meal frequency, breastfed 6-23 months & 406 & 378 & 93.1 & $90.1,95.3$ \\
\hline Minimum acceptable diet, breastfed 6-23 months & 406 & 350 & 86.2 & $82.5,89.4$ \\
\hline
\end{tabular}

children breastfed within one hour after birth for rural India $(39.8 \%)^{12}$ Punjab $(43.9 \%)^{13}$ and District Ludhiana $(45.9 \%) .{ }^{13}$ Khan et $\mathrm{al}^{14}$ in a study done in Delhi observed that $37.2 \%$ of children less than 24 months had early initiation of breastfeeding. Victor et a ${ }^{15}$ from a secondary analysis of the 2010 Tanzania Demographic and Health Survey showed that $46.1 \%$ (95\% CI: 43.44, 48.76) of the mothers initiated breastfeeding within one hour of birth. Lutter et a ${ }^{16}$ also observed similar findings in other developing countries, however, it was lower than that observed in Gazipur District, Bangladesh (67.3\%). ${ }^{17}$

The main reasons for not initiating breastfeeding early were having no breast milk (28.4\%), no knowledge (20.7\%) and caesarian section $(10.2 \%)$. Wu et al in a study done in a rural county in Hebei Province, China indicated that infant feeding practices were poor and the main reasons for not initiating breastfeeding early were caesarean section, seeing the baby later than one hour after delivery, no knowledge and having no breastmilk. ${ }^{18}$

Improper feeding practices and diarrheal diseases are important determinants of malnutrition. In India, introduction of liquids and solids or semi-solids often take place before the recommended age of six months, which increases their exposure to pathogens, putting them at greater risk of contracting diarrhoeal diseases. Less than half $(46 \%$ and $33 \%$ ) of children younger than 6 months are exclusively breastfed in India ${ }^{8}$ and in rural Punjab ${ }^{13}$ respectively, which is lower as compared to observations $(75.9 \%)$ revealed in the present study. The reason might be that in present study exclusive breastfeeding was based on 24 hour recall rather than a longer recall period. This may lead to overestimation of exclusive breastfeeding as some infants who are given other liquids irregularly may not have received them in the day before the survey and therefore this short recall may have missed these infants.

Saxena and Kumari in Doiwala block, Dehradun, India observed that $77.4 \%$ had exclusive breastfeeding. ${ }^{19}$ Sultana et al in Bangladesh also found that $82.7 \%$ had exclusive breastfeeding, ${ }^{17}$ while Gyampoh et al in Accra Ghana assessed mother-child pairs accessing child welfare services at Ghana health service's Child welfare Clinic (CWC) and observed that about $81 \%$ of the children less than 6 months were exclusively breastfed in preceding 24 hours. ${ }^{20}$ In agreement with studies conducted in developing countries, $5,10,12,21$ our study also revealed that exclusive breastfeeding rate dropped from $82.2 \%$ for children less than 2 months to $69.6 \%$ for children under 6 months $\left(\chi^{2}=4.45, \mathrm{df}=2, \mathrm{p}=0.1081\right)$. It was also observed that $79.8 \%$ of children less than 4 months were exclusively breastfed, thus decline in exclusive breastfeeding took place after 4 months of age (Table 2).

Almost all children $(98.4 \%)$ in the study have been breastfed, consistent with NFHS-3 figures for India $(96 \%)^{10}$ and Punjab (94.1\%). ${ }^{11}$ Similar figures $(99.2 \%)$ were reported by Patel et $\mathrm{al}^{8}$ who analyzed NFHS-3 figures using these WHO indicators. Information on bottle feeding is useful because of potential interference of bottle feeding with optimal breastfeeding practices and the association between bottle feeding and increased diarrhoeal disease morbidity and mortality. Bottles with nipple are particularly prone to contamination. ${ }^{4}$ About one quarter of all children in the present study was bottle fed. Authors from India ${ }^{14,22}$ and abroad $^{23}$ have reported similar findings. A significant increase in bottle feeding was observed from $13.8 \%$ among children under 6 months of age to $35.2 \%$ for children 12 months to less than 24 months of age $\left(\chi^{2}=38.38, \mathrm{df}=2\right.$, $\mathrm{p}<0.0001$ ) (Table 2). Victor et al also supported similar association. $^{15}$

The continuation rate of breastfeeding of $70.9 \%$ after completion of one year found in the present study was similar to observations made in several other studies, $5,14,23$ which is indicative of the continuation of traditional practice of breast feeding. Other authors ${ }^{8,15}$ reported higher figures, while Mondal et $\mathrm{al}^{24}$ observed lower rate for tribal population in West Bengal, India. Similarly continued breastfeeding rate of $54.7 \%$ at two years was in conformity with other secondary analysis of DHS in Tanzania ${ }^{15}$ and Pakistan ${ }^{23}$ but lower than that 
demonstrated by other studies in India. ${ }^{8,21}$ We found that Insufficient milk secretion and unawareness were the most common factors for discontinuing breastfeeding at one year and two years, which is also reflected by significant increase in bottle feeding rate with increase in age of children.

In the present study, the proportion of infants aged 6-8 months who received solid, semi-solid or soft food, in addition to breast milk was better at $89.5 \%$ as compared to rural India $(56.5 \%)^{12}$ and rural Punjab $(70.0 \%) .^{13}$ Sultana et al also found that the rate of timely starting of complimentary feeding was $83.1 \% .{ }^{17}$ However, a wide variation has been reported by other studies ranging between $29.8 \%$ and $72.7 \% .5,14,21,22,25$ Minimum dietary diversity was observed in $87.0 \%$ of the children between 6 and 23 months, in agreement with study done in India. ${ }^{25}$ Also a significant increase in prevalence of minimum dietary diversity with increase in age from 6 months to 23 months observed in the present study was similar to findings demonstrated in other studies. , $, 10,11,13^{2}$

\section{CONCLUSION}

Breastfeeding in the present study is almost universal, however prevalence of early initiation, exclusive \& continuation of breastfeeding at one and two years is below the desired targets. Conversely higher rate of bottle feeding is worrisome. Insufficient milk secretion and inadequate knowledge about breastfeeding were the main reasons for present status of these indicators. The improvement will require strengthening of health education for target populations having sub-optimal breastfeeding practices, regarding IYCF guidelines with a special focus on correct positioning of child at breast and importance of breast milk.

\section{ACKNOWLEDGEMENT}

The authors acknowledge the role of Dr. RK Sachar, former Professor \& Head, Dept. of Community Medicine, DMC \& Hospital, Ludhiana for providing valuable guidance during planning of the study.

\section{REFERENCES}

1. Ministry of Human Resource Development, Department of Women and Child Development (Food and Nutrition Board) Government of India. National guidelines on infant and young child feeding 2004.

2. Cooperative for Assistance and Relief Everywhere, Inc. (CARE). Infant and young child feeding practices, collecting and using data: A step-by-step guide 2010.

3. World Health Organization. WHO/UNICEF/IFPRI/UCDavis/
FANTA/AED/USAID. Indicators for assessing infant and young child feeding practices. Part 3: Country Profiles. Geneva 2008.

4. World Health Organization. Indicators for assessing infant and young child feeding practices. Part I: Defintions. Conclusions of a consensus meeting held 6-8 November 2007 in Washington D.C., USA. Geneva, WHO 2008.

5. Marriot BP, White A, Hadden L, Davies JC, Wallingford JC. World Health Organization (WHO) infant and young child feeding indicators: association with growth measures in 14 low-income countries. Matern Child Nutr 2012; 8:354-370.

6. World Health Organization. WHO/UNICEF/IFPRI/UCDavis/ FANTA/AED/USAID. Indicators for assessing infant and young child feeding practices. Part 2: Measurement. Geneva 2010.

7. Jones $A D$, Ickes SB, Smith LE, Mbuya MNN, Chasekwa B, Rebecca A, et al. World Health Organization infant and young child feeding indicators and their associations with child anthropometry: a synthesis of recent findings. Matern Child Nutr 2014; 10:1-17.

8. Patel A, Badhoniya N, and Dibley M. Breastfeeding and infant feeding practices in India- A review of Demographic and Health Surveys and National Family Health Surveys. Solution Exchange for $\mathrm{MCH}$ Community Newsletter, Breastfeeding Month Special; 2008.

9. Ministry of Health and Family welfare, Government of India. Guidelines for enhancing optimal infant and young child feeding practices 2013.

10. International Institute for Population Sciences (IIPS) and Macro International. National Family Health survey (NFHS 3), 2005-06: India: Volume I. Mumbai: IIPS 2007.

11. International Institute for Population Sciences (IIPS) and Macro International. National Family Health survey (NFHS 3), India, 2005-06: Punjab. Mumbai: IIPS 2008.

12. Ministry of Health and Family Welfare, Government of India. District Level Household and Facility Survey (DLHS 3), 2007-08: Facts Sheets India. Mumbai: International Institute for Population Sciences 2009.

13. Ministry of Health and Family Welfare, Government of India. District Level Household and Facility Survey (DLHS 3), 2007-08: Punjab, India. Mumbai: International Institute for Population Sciences 2010.

14. Khan AM, Kayina P, Agrawal P, Gupta A, and Kannan AT. A study on infant and young child feeding practices among mothers attending an urban health centre in East Delhi. Indian J Public Health 2012; 56:301-304.

15. Victor R, Balnes SK, Agho KE, and Dibley MJ. Determinants of breastfeeding indicators among children less than 24 months of age in Tanzania: a secondary analysis of the 2010 Tanzania Demographic and Health Survey. BMJ Open 2013; 3:e001529.

16. Lutter CK, Daelmans BMEG, de Onis MD, Kothari MT, Ruel MT, Arimond $\mathrm{M}$, et al. Undernutrition, poor feeding practices, and low coverage of key nutrition interventions. Pediatrics 2011; 128(6): e1418-1428.

17. Sultana S, Hoque A, and Saleh F. Infant and young child-feeding practices and their nutritional status in a National Nutritional Programme area in Bangladesh: A cross-sectional study. J Hum Nutr Food Sci 2014; 2:1028.

18. Wu Q, Scherpbier RW, van Velthoven MH, Chen L, Wang W, Li Y, et al. Poor infant and young child feeding practices and sources of caregivers' feeding knowledge in rural Hebei Province, China: findings from a cross-sectional survey. BMJ Open 2014; 4: e005108.

19. Saxena V, and Kumari R. Infant and young child feeding- Knowledge and practices of ASHA workers of Doiwala block, Dehradun district. Ind J Comm Health 2014; 26: 68-75.

20. Gyampoh S, Otoo GE, and Aryeetey RNO. Child feeding 
knowledge and practices among women participating in growth monitoring and promotion in Accra, Ghana. BMC Pregnancy Childbirth 2014; 14:180.

21. Sinhababu A, Mukhopadhyay DK, Panja TK, Saren AB, Mandal NK, and Biswas AB. Infant- and young child feeding practices in Bankura District, West Bengal, India. J Health Popul Nutr 2010; 28:294-299.

22. Das N, Chattopadhyay D, Chakraborty S, and Dasgupta A. Infant and young child feeding perceptions and practices among mothers in a rural area of West Bengal, India. Ann Med Health Sci Res 2013; 3:370-375.
23. Hanif HM. Trends in breastfeeding and complementary feeding practices in Pakistan, 1990-2007. International Breastfeeding Journal 2011;6:15.

24. Mondal TK, Sarkar AP, Shivam S, and Thakur RP. Assessment of infant and young child feeding practice among tribal women in Bhatar block of Burdwan district in West Bengal, India. Int J Med Sci Public Health 2014; 3:324-326.

25. Singhal P, Garg SK, Chopra H, Jain S, Bajpai SK, and Kumar A Status of infant and young child feeding practices with special emphasis on breast feeding in an urban area of Meerut. J Dental and Medical Sciences 2013; 7:07-11.

\section{Authors Contribution:}

MS: Concept and design of the study, reviewed the literature, collected data and analyzed statistically, manuscript preparation (first draft), editing and critical revision of the manuscript. SS: Concept and design of the study, collected data and review of literature, analyzed statistically, helped in preparing first draft of manuscript, editing and critical revision of the manuscript. AC: Conceptualized study, literature search, statistically analyzed and interpreted, helped in preparing first draft of manuscript and critical revision of the manuscript. PK: Data analysis, helped in manuscript preparation, editing and review of study. SG: Data analysis, helped in manuscript preparation, editing and review of study.

Source of Support: Nil, Conflict of Interest: None declared. 